\title{
A TRANSCRIAÇÃO DO MUNDO PELA EXPERIÊNCIA: ESBOÇO PARA UMA EDUCAÇÃO ESTÉTICA
}

\author{
THE TRANSCREATION OF THE WORLD BY EXPERIENCE: \\ ESSAY OF THE AESTHETIC EDUCATION
}

Rogério de Almeida

Livre-docente em Cultura e Educação, professor associado da Faculdade de Educação da Universidade de São Paulo (FEUSP)

São Paulo - SP, Brasil. rogerioa@usp.br

\author{
Alberto Filipe de Araújo \\ Professor catedrático aposentado do Instituto de Educação da Universidade do Minho (UMinho) \\ Braga, Portugal. \\ afaraujo@ie.uminho.pt
}

\begin{abstract}
Resumo: O objetivo deste artigo é investigar as artes como processo de transcriação pelo qual artista e apreciador tornam-se coautores dos sentidos que emanam da experiência estética. A hipótese em questão é a de que as obras de arte operam uma mediação estética entre o humano e o mundo, pela qual o mundo passa a ser sentido, compreendido e expresso. Esse processo requer uma educação de sensibilidade que não seja a imposição de determinadas obras canônicas ou modos preestabelecidos de fruição dessas obras, mas exercício de sensibilidade e compreensão das múltiplas possibilidades dos modos de viver. Nessa perspectiva, a própria vida torna-se obra de arte. A inclinação teórico-metodológica que inspira este artigo provém do perspectivismo nietzschiano (NIETZSCHE, 1998; LAROSSA, 2009) e da hermenêutica simbólica (RICOEUR, 1969; DURAND, 1997). Os resultados da pesquisa apontam para a urgência de uma educação de sensibilidade que considere a importância das experiências estéticas no âmbito da formação, com o objetivo de se chegar a ser o que se é.
\end{abstract}

Palavras Chave: Educação de sensibilidade. Estética. Hermenêutica. Perspectivismo. Transcriação.

\begin{abstract}
The aim of this paper is to investigate the arts as a process of trans-creation through which artist and connoisseur become co-authors of the meanings emanating from the aesthetic experience. The hypothesis here in question is that works of art operate an aesthetic mediation between the human and the world, whereby the world is meant, understood and expressed. Such process requires an education of our sensitivity that is not the imposition of certain canonical works or pre-established modes of fruition of such works, but the sensitivity practice and understanding of the multiple possibilities of ways of living. From this perspective, life itself becomes a work of art. The theoretical-methodological approach that inspires this paper stems from the Nietzschean perspectivism (NIETZSCHE, 1998; LAROSSA, 2009) and symbolic hermeneutics (RICOEUR, 1969; DURAND, 1997). After serious consideration of such matters it is the authors contention that there is an urgency of a sensitivity education that recognizes the importance of aesthetic experiences for one to become what one is.
\end{abstract}

Key-words: Sensitivity Education. Aesthetics. Hermeneutics. Perspectivism. Transcreation.

\section{Para citar - (ABNT NBR 6023:2018)}

ALMEIDA, Rogério de; ARAÚJO, Alberto Filipe de. A transcriação do mundo pela experiência: esboço para uma educação estética. Eccos - Revista Cientifica, São Paulo, n. 53, p. 1-18, e16676, abr./jun. 2020. Disponível em: https://doi.org/10.5585/eccos.n53.16676. 
Não existem temas nobres e temas vulgares, muito menos episódios narrativos importantes e episódios descritivos acessórios.

Não existe episódio, descrição ou frase que não carregue em si a potência da obra.

Porque não há coisa alguma que não carregue em si a potência da linguagem.

Jacques Rancière, 2009, p. 37

Estruturado em quatro secções, este artigo 1) discute o problema da definição das artes (termo utilizado no plural para marcar sua multiplicidade de formas), 2) passa pela questão da transcriação como elemento importante para a compreensão hermenêutica do mundo, em que as múltiplas perspectivas são acionadas, 3) reflete sobre a estética da experiência e 4) finaliza com um esboço para uma educação estética que privilegie a experiência e a sensibilidade no trato com o mundo. $\mathrm{O}$ objetivo é compreender como artista e apreciador convertem-se em coautores dos sentidos transcriados pelas obras de arte, processo que compreende a importância da experiência estética na educação de sensibilidade. Essa educação concebe a própria vida como obra de arte, justificando-se, portanto, esteticamente, e objetivando tornar-se o que se é. Guiam as análises o perspectivismo nietzschiano e a hermenêutica simbólica inspirada em Paul Ricoeur e Gilbert Durand.

\section{0 problema da definição das artes}

Um dos problemas que está no cerne da definição das artes é que os conceitos que buscam abarcá-las são, mais cedo ou mais tarde, desafiados pelo surgimento de obras que escapam ao conjunto circunscrito por eles. Poder-se-ia conjecturar que os conceitos não são propriamente necessários para a realização das artes, ou mesmo para sua apreciação, mas é inegável que o é para a filosofia, cujo modus operandi é, ao menos para Deleuze e Guattari (1992), a criação de conceitos. E deve ser também para a educação, principalmente quando se ocupa das sensibilidades e dos modos sensíveis de compreensão do mundo.

Entretanto, quando examinamos o conjunto das definições propostas para as obras de arte, nenhum conceito parece satisfazer, ou por serem muito abrangentes ou por serem muito restritivos, ou por serem essencialistas ou meramente funcionais. Mas a dificuldade em questão não se resume somente às artes. A própria filosofia tem dificuldade em se definir e certamente não são poucos os filósofos que se opõem à definição proposta por Deleuze e Guattari. Parece haver, portanto, um limite de alcance do pensamento lógico em sua tarefa de apresentar 
enunciados que satisfaçam as condições necessárias e suficientes para definir aquilo a que se propõem.

Isso não significa que abdicaremos de estudar as obras de arte pela dificuldade de definilas, ou que renunciaremos às definições, ainda que insuficientes, provisórias ou mesmo conflitantes, já que a hermenêutica pode colocar em questão justamente o alargamento da compreensão pelo reconhecimento da pluralidade de perspectivas de compreensão (RICOEUR, 1969). Procuraremos, desse modo, a partir do impasse entre as definições, mobilizar os elementos funcionais que estão em jogo na relação com a obra de arte, tendo em vista que artista e apreciador são coautores desse processo, ainda que desempenhem papéis distintos. Isso significa que a definição da obra de arte atrela-se ao contexto em que se insere e sobre o qual intervém, daí a necessidade do reconhecimento de perspectivas, no sentido dado por Nietzsche (1998, p. 109), de que “existe apenas uma visão perspectiva, apenas um 'conhecer' perspectivo", o que enseja a busca por olhares díspares para maior "objetividade" do conceito.

Desse modo, as reiteradas críticas às definições tradicionais de arte - miméticas, expressionistas e formalistas - parecem esquecer que em seus contextos enunciativos respondiam, mais ou menos adequadamente, a um certo programa a que visavam. A teoria da imitação, por exemplo, serviu para que Aristóteles abstraísse da tragédia grega sua finalidade de educar as emoções por meio da catarse. Na visão de Nietzsche (1999, p. 132), entretanto, para além dos fenômenos médicos e morais da tragédia, havia outro, que chama de "jogo estético", e que nada tem a ver com o julgamento crítico e abstrato das obras de arte. O "ouvinte estético" da tragédia grega vivenciava o mito, "a imagem concentrada do mundo" (NIETZSCHE, 1999, p. 132).

De modo análogo, quando as definições expressionistas reduzem a arte à expressão das emoções e defendem a emoção estética, ou quando os formalistas buscam o significado na própria forma, não estão propriamente errados quanto ao programa a que visavam, já que a expressão da emoção serve muito bem à estética romântica, do mesmo modo que a forma explica bem a arte abstrata, o impressionismo e o cubismo da virada do século XIX para o XX.

Quanto às definições mais contemporâneas, parecem repetir o mesmo padrão: conseguem ajustar o conceito a dado conjunto de obras de arte, mas não a todas, de modo que os contraexemplos terminam por frustrar o intento. Adilson Koslowski (2013, p. 5-7) enumera diversas dessas definições, como é o caso, por exemplo, da teoria institucional de Dickie, que subordina a arte ao julgamento das pessoas que atuam em nome de uma determinada instituição social; da teoria histórico-intencional de Jerrold Levinson, pautada pelas intenções do artista de que sua obra, seja ela qual for, seja vista como obra de arte; Berys Gaut defende a teoria do 
agrupamento do conceito de arte, com uma lista de dez propriedades definitórias do que é arte ou não. Todas essas abordagens receberam diversas críticas e contraexemplos que mostraram suas insuficiências. Não é difícil imaginar que, diante de tanta dificuldade, surgisse quem desistisse do problema, como Warburton, que prefere tratar de obras particulares, ou mesmo Nelson Goodman, que desloca a questão para “quando há arte?” (KOSLOWSKI, 2013, p. 7).

Uma alternativa ao problema é admitir que o pensamento lógico-racional não pode ser, ao menos em matéria de arte, prescritivo, e que seu afã de uma definição única e universal pode muito bem ser moderada por uma perspectiva pluralista, em que se procura trabalhar com definições de arte, de acordo com as estratégias argumentativas. Abre-se mão do intento de se buscar a definição definitiva, de resto impossível - é o que a história da filosofia e da arte permitem inferir -, para se trabalhar com as noções estrategicamente mais adequadas para determinados intentos teóricos.

Nessa perspectiva, consideramos haver, quando trazemos a arte e a estética para o campo da educação, duas grandes concepções (ou meta-teorias) norteadoras do papel da arte numa educação de sensibilidade: a primeira, de matriz racionalista-iluminista-idealista, que alinhava a arte com os demais procedimentos críticos e metodológicos de estabilização de enunciados e a quer com uma função cognitiva, moralizadora ou catártica, portanto como modo de explicação ou representação do mundo, como modelo de valoração dos costumes ou meio de alívio das tensões pela descarga emocional; a segunda, de matriz hermenêutica-simbólicatrágica, que considera a arte como forma simbólica (CASSIRER, 1994), expressão de imaginários (DURAND, 1997), com função de pluralização das perspectivas (NIETZSCHE, 1998), desestabilização de sentidos (FAVARETTO, 2011) e educação da sensibilidade (DUARTE JUNIOR, 2004; PILLOTTO, 2007), portanto, em estreita relação com a experiência e a vida.

\section{Artes como transcriação}

É nesta última perspectiva meta-teórica que se insere a noção de transcriação. E aqui optamos pelo termo noção, por entender que é mais abrangente, aberto e provisório, menos restritivo que definição, menos peremptório que conceito. A transcriação é compreendida como um processo dinâmico que envolve elementos presentes no engendramento, na elaboração de uma obra de arte e em sua recepção pelos apreciadores, que operam como coautores dos sentidos das obras. Quanto menos desdobramentos perspectivos uma obra gera, tanto menor 
seu interesse para a formação, porque ela teria menor potencial de desestabilização de enunciados, tendendo a se reduzir a uma mera ilustração de um discurso qualquer.

Como as obras de arte mobilizam imaginários (DURAND, 1997), suas operações, capitaneadas pela faculdade da imaginação, agem diretamente nas sensações, isto é, na vida psíquica de quem as aprecia, já que "muito longe de ser faculdade de 'formar' imagens, a imaginação é potência dinâmica que 'deforma' as cópias pragmáticas oferecidas pela percepção" (BACHELARD, 2004, p. 5). É por isso que convém menos tratar as obras como criação - humano como símile do deus criador -, em que algo passa a existir ab ovo, do que como transcriação, em que os elementos existentes, transcriados pela intencionalidade humana (imaginação, razão, emoção etc.), são deformados e reformados pelas sensações.

A base, portanto, de toda obra são as sensações, como resultado complexo das interações perceptivas, afetivas, cognitivas etc., que fornecem a matéria-prima a ser transformada pela imaginação em obras de arte. E se a percepção, os afetos, os saberes, enfim, as sensações, são a matéria-prima da imaginação, e a própria imaginação o processo dinâmico que as transforma, então o fundamento das obras não pode derivar da razão (funcionalidade, utilidade ou finalidade), mas da dimensão estética. Isso não quer dizer que as obras não tenham funcionalidade, utilidade, finalidade ou que a razão não opere no engendramento das artes. Não se trata de isolar ou proscrever a razão, mas de compreendê-la em consonância com a imaginação, já que sem o conluio dessas tendências dificilmente haveria o impulso criador.

É nesse contexto que nos cabe indagar se efetivamente é possível a criação. O que os artistas concebem, suas realizações, pode ser chamado efetivamente de criação, no sentido de trazer à existência algo que, sob qualquer outra forma, jamais existiu? Clément Rosset (1989, p. 183) afirma que não, sendo toda criação impossível, "se se entende por criação uma modificação trazida ao estatuto do que existe", e isso porque não podemos modificar o acaso. O artista, então, celebra o que existe acrescentando mais acaso ao acaso, essa é a única criação possível, experimentar esteticamente o acaso do mundo por meio da "aceitação sem reticências do acaso ambiente, e acolhimento benevolente do acaso de seus próprios achados" (ROSSET, 1989, p. 186). A criação contribui com o acaso do que existe acrescentando "arranjos imprevistos - ainda que em última instância previsível - ao jogo sem regras da existência" (ROSSET, 1989, p. 186). Mais do que expressar uma faculdade "criadora", a criação estética apresenta-se como "a expressão de um gosto" (p. 183): 
Esse "gosto", pelo qual a filosofia trágica designa simultaneamente o que é chamado ora talento, ora gênio, ora potência criadora ou capacidade produtiva, não significa uma aptidão em transcender o acaso em criações que escapariam ao acaso, mas uma arte (originalmente sofística) de discernir, no acaso dos encontros, aqueles que dentre eles são agradáveis: arte, não de "criação", mas de antecipação (prever, por experiência e delicadeza, os bons encontros) e de retenção (saber "reter" sua obra num desses bons encontros, o que significa que se pode apreender no voo o momento oportuno) (ROSSET, 1989, p. 183).

A obra é um processo de organização, de corte, retoque e montagem, que estabiliza determinado arranjo de elementos por meio de certas escolhas estéticas, mais ou menos intencionais; que se vale das sensações (ideias, emoções, impressões etc.); que expressa um gosto e se abre à prova de outros gostos.

Se a arte não pode criar, no sentido estrito do termo, por outro lado pode expressar os gostos que experimentamos continuamente no trato com as coisas do mundo. Por mais estranha, dolorosa ou complexa que seja a experiência com o real, sua transcriação em arte pode provisionar prazer, injetar mais intensidade ao modo como experimentamos a vida. Admitida essa perspectiva, que se ancora na filosofia trágica de Nietzsche e Rosset, admite-se que a arte não está restrita aos objetos, mas ligada à vida:

A vida como obra de arte inscreve-se como sua afirmação, como amor fati, ou seja, amor pelo destino, não como futuro preestabelecido, mas como o sentido que dou à minha história, somatória das escolhas que faço com o fortuito da existência. Daí a necessidade de uma pedagogia da escolha, que restabeleça a faculdade criativa na própria inscrição da arte de viver (FERREIRA SANTOS; ALMEIDA, 2012, p. 151).

O termo transcriação vicejou no campo linguístico e definiu um modo de traduzir obras poéticas que demandam recriações em outra língua. No campo da tradução, podemos entender a transcriação como uma "transposição criativa" (JAKOBSON apud CAMPOS, 1969, p. 110), já que não se trata da reconstituição da mensagem, mas "do sistema de signos em que está incorporada esta mensagem, da informação estética, não da informação meramente semântica" (CAMPOS, 1969, p. 100). A tradução não se restringe, entretanto, a meros processos de câmbio linguístico, e acrescentaríamos também à recriação estética interlínguas, embora funcionem como modelo analógico para a compreensão do próprio termo compreensão. Isso significa que a compreensão de um texto, de uma situação, de uma época, intenção ou mesmo gesto é um ato de tradução. George Steiner (2005, p. 53) explica esse ato recorrendo ao termo francês interprète: "Um ator é interprète de Racine; um pianista dá une interprétation a uma sonata de Beethoven. Por meio do envolvimento de sua própria identidade, um crítico torna-se un interprète de (alguém que dá vida a) Montaigne ou Mallarmé”.

Para Steiner (2005, p. 54), a "tradução diacrônica no interior da própria língua é tão constante, nós a realizamos tão inconscientemente que raramente paramos para observar seja 
sua complexidade formal, seja o papel decisivo que ela exerce na própria existência da civilização". Como implicação, temos de reconhecer que a experiência do passado é um construto verbal e que a cultura não poderia existir se não fossem os sentidos múltiplos em torno do sentido unificado da palavra. Essa multiplicidade de sentidos dada pela tradução impede o silêncio definitivo da cultura, pois é o atrito da vontade de compreender com a imprecisão sempre renovada da palavra (do que se compreende dela) que põem em movimento a compreensão. Entretanto, não compreendemos apenas a palavra, isoladamente, mas, como demonstrou Ricoeur (2008), a própria proposição de mundo que essa palavra, urdida em texto, emana. E essa compreensão de mundo, por sua vez, provoca no intérprete a compreensão de si.

Desse modo, o conhecimento é uma ato de tradução, não meramente de passagem de uma forma a outra, de uma língua a outra, de uma gramática ou de um imaginário, mas sobretudo de transcriação de construtos simbólicos, ou seja, de formas simbólicas como a linguagem, a religião e, no caso em questão, as artes (CASSIRER, 1994). Assim, a tradução é um "caso especial do arco de comunicação que cada ato de linguagem bem-sucedido fecha no interior de uma dada língua". Portanto, a recepção de uma mensagem é um ato de tradução: "entre línguas ou no interior de uma língua, a comunicação humana é igual à tradução" (STEINER, 2005, p. 72).

Compreender assemelha-se a traduzir na mesma proporção em que ler um gesto, um texto ou uma imagem implica conferir-lhe sentido. A compreensão decorrente das leituras, das traduções, das transcriações de mundo é um ato de interpretação. Por esta perspectiva, embora as artes possam ser apreciadas de distintas formas, o que une uma obra a quem a aprecia não é a intenção do artista ou o sentido oculto supostamente escondido nela, mas a possibilidade de interpretação, de compreensão, seja da obra, seja do mundo a que ela eventualmente alude, seja do próprio intérprete diante da obra transcriada a lhe exigir transcriação. É o processo descrito poeticamente por Fernando Pessoa (1980, p. 104):

\author{
O poeta é um fingidor \\ Finge tão completamente \\ Que chega a fingir que é dor \\ A dor que deveras sente. \\ E os que lêem o que escreve, \\ Na dor lida sentem bem, \\ Não as duas que ele teve, \\ Mas só a que eles não têm. \\ E assim nas calhas da roda \\ Gira, a entreter a razão, \\ Esse comboio de corda \\ Que se chama coração.
}


O processo é circular: forjamos racionalmente nossa dor, transcriamo-la em obra, para que então seja lida e transcriada em sentimento pelos leitores. E é essa dor traduzida que realimentará o circuito no qual razão e sentimento se retroalimentam na mediação do homem consigo e com os outros:

O poeta não mente sua dor, mas a finge de tal forma que a dor fingida é a que ele mesmo sente. Esse duplo da dor, dor transformada esteticamente em palavras, possibilita a comunicação, por meio da mediação poética, entre o poeta e os leitores. Nessa relação, o leitor sente, não a dor do poeta - nem a primeira, sentida, nem a segunda, seu duplo poético - mas a que ele não tem. [...] O sentido do texto irrompe, então, da relação do leitor com o texto, num complexo jogo de mediação simbólica e experiência estética (ALMEIDA, 2011, p. 173).

O exame das artes sugere que a relação do homem com o mundo é transcriativa, pois as mediações se dão menos por invenção que por transformação das experiências, as quais podem assumir sua condição estética. A língua, as linguagens, as artes não se reduzem à comunicação de fatos, à expressão de pensamentos ou ao embelezamento do mundo, dimensões secundárias dos discursos humanos, no entender de George Steiner, para quem:

\begin{abstract}
Os potenciais da ficção, da contrafactualidade, de uma futuridade incerta caracterizam profundamente as origens e a natureza da linguagem. Eles a diferenciam ontologicamente dos diversos sistemas de signos disponíveis no mundo animal, determinam a maneira peculiar e geralmente ambígua da consciência humana e tornam criativas as relações desta consciência com a "realidade". Com a linguagem, boa parte da qual é voltada para dentro de nossas próprias pessoas, rejeitamos a inevitabilidade empírica do mundo (STEINER, 2005, p. 494-495).
\end{abstract}

A ficção literária, as artes plásticas, a música ou o cinema são, pois, expressões estéticas dessa mediação simbólica entre a pessoa e o mundo, pela qual o imaginário, tal como o concebeu Gilbert Durand (1988; 1997), realiza sua função de eufemização, que nada mais que é a própria função da imaginação, que opera como fator importante de equilíbrio biopsicossocial. "Negar eticamente o negativo", que é o que a eufemização faz, corresponde simbolicamente à "negação do nada, da morte e do tempo" (DURAND, 1988, p. 117).

Essa função da imaginação, de eufemização, realiza-se por meio da mediação simbólica. E aqui é importante diferenciar símbolo de signo, já que, enquanto este, em sua arbitrariedade, refere-se a um objeto sensível, a um referente exterior, o símbolo é "signo que remete a um indizível e invisível significado, sendo assim obrigado a encarnar concretamente essa adequação que lhe escapa, pelo jogo das redundâncias míticas, rituais, iconográficas que corrigem e completam inesgotavelmente a inadequação" (DURAND, 1988, p. 19). O símbolo busca preencher essa inadequação que irrompe entre a insignificância, irracionalidade, insensibilidade do mundo concreto e os signos significantes, racionais e sensíveis da linguagem. Encarna, portanto, um sentido. Embora a mediação operada pelos símbolos entre a linguagem 
humana e o mundo seja sempre insuficiente em sua pretensão de exatidão, é por outro lado rica na multiplicação de sentidos e possibilidades interpretativas, mantendo em movimento o processo dinâmico que caracteriza as culturas.

Para concluir esta secção, é preciso ter em mente que leitor/espectador/apreciador é parte constitutiva do processo chamado de transcriação. Não é somente por meio da elaboração de obras que se opera a mediação do mundo, lê-las, compreendê-las, traduzi-las, interpretá-las são atos complexos e - dada a inadequação inerente do símbolo e a imprecisão renovada da língua - transcriativos. Somos, portanto, coautores das obras com as quais interagimos: "leitura e interpretação são, em última análise, 'tradução' que dá vida, que empresta vida à obra gelada, morta. Através da 'tradução', a minha própria linguagem torna-se uma com a do criador" (DURAND, 1998, p. 252).

Essa dimensão transcriativa estabelecida entre as obras e seus apreciadores, de ordem simbólica e imaginária, propicia uma experiência de inflexão estética, que não se limita à contemplação de objetos, mas se espraia pela própria vida e a intensifica. Na próxima secção faremos algumas considerações sobre a estética da experiência como preâmbulo para pensarmos uma educação que coloque a sensibilidade no centro do processo formativo.

\section{Considerações sobre a estética da experiência}

Jorge Larrosa tem se dedicado a explorar o tema da experiência, fazendo parte de um ainda - restrito número de autores que examinaram a questão. Para ele, "a experiência é o que nos passa, o que nos acontece, o que nos toca. Não o que se passa, não o que acontece, ou o que toca. A cada dia se passam muitas coisas, porém, ao mesmo tempo, quase nada nos acontece" (2014, p. 18). Primeiro, porque, segundo o autor, estamos soterrados de informações, de conhecimentos; segundo, porque há um excesso de opinião, somos o tempo todo instados a opinar; terceiro, por falta de tempo:

A velocidade com que nos são dados os acontecimentos e a obsessão pela novidade, pelo novo, que caracteriza o mundo moderno, impedem a conexão significativa entre acontecimentos. Impedem também a memória, já que cada acontecimento é imediatamente substituído por outro que igualmente nos excita por um momento, mas sem deixar qualquer vestígio. O sujeito moderno não só está informado e opina, mas também é um consumidor voraz e insaciável de notícias, de novidades, um curioso impertinente, eternamente insatisfeito. Quer estar permanentemente excitado e já se tornou incapaz de silêncio. Ao sujeito do estímulo, da vivência pontual, tudo o atravessa, tudo o excita, tudo o agita, tudo o choca, mas nada lhe acontece. Por isso, a velocidade e o que ela provoca, a falta de silêncio e de memória, são também inimigas mortais da experiência (LARROSA, 2014, p. 22). 
Larrosa aponta o excesso de trabalho como entrave à experiência. A regulação das atividades e a acomodação ao modo como as coisas se dão, acrescidas de uma ideologia que combina otimismo, progressismo e agressividade, impedem que paremos e, sem parar, nada nos acontece. "Nós somos sujeitos ultrainformados, transbordantes de opiniões e superestimulados, mas também sujeitos cheios de vontade e hiperativos" (LAROSSA, 2014, p. 24).

O sujeito da experiência não é, para Larrosa, o sujeito da informação, da opinião, do trabalho ou do saber. O sujeito da experiência é um "território de passagem", um sujeito "exposto":

\begin{abstract}
Do ponto de vista da experiência, o importante não é nem a posição (nossa maneira de pormos), nem a "oposição" (nossa maneira de opormos), nem a "imposição" (nossa maneira de impormos), nem a "proposição" (nossa maneira de propormos), mas a "exposição", nossa maneira de "ex-pormos", com tudo o que isso tem de vulnerabilidade e de risco (LARROSA, 2014, p. 26).
\end{abstract}

Nessa acepção, o sujeito da experiência é um território de passagem afetado pelas paixões, o que quer dizer que está fora de prumo, fora de si, tensionado pela vida e pela morte, o que possibilita produzir outras formas de saber, o saber da experiência. Para explicar esse saber, Larrosa (2014, p. 31-24) retoma os tempos anteriores à ciência moderna e à sociedade capitalista para resgatar a noção de páthei máthos, como uma aprendizagem no e pelo padecer, no e por aquilo que nos acontece. Não se trata de um saber que tende à objetividade ou à verdade, mas de um saber ligado à existência do homem concreto e singular, saber particular, subjetivo, relativo, contingente, pessoal. O saber da experiência revela o sentido ou o semsentido de uma existência encarnada, de uma vida atravessada por acontecimentos que só podem ser significados do interior, por aquele que os viveu.

Com a ciência moderna, a experiência se converte em experimento e o conhecimento se volta para a leitura do mundo, para a detecção das regularidades a partir das quais se impõem as políticas da verdade, da realidade e do domínio. O conhecimento deixa de ser páthei máthos para se tornar mathema, uma acumulação progressiva de verdades objetivas e exteriores aos homens.

A experiência, então, estaria em risco devido aos modos de vida contemporâneos, já que o século XX teria colocado em "funcionamento massivo uma série de dispositivos que tornam impossível a experiência, que falsificam a experiência ou que nos permitem nos desembaraçarmos de toda a experiência" (LAROSSA, 2014, p. 53). O autor então indaga sobre a pertinência de usar o termo experiência: 
Já não há experiência porque vivemos nossa vida como se não fosse nossa, porque não podemos entender o que nos acontece, porque é tão impossível ter uma vida própria quanto uma morte própria [...] porque a experiência daquilo que nos acontece é que não sabemos o que nos acontece, porque a experiência de nossa língua é que não temos língua, que estamos mudos, porque a experiência de quem somos é não sermos ninguém (LARROSA, 2014, p. 54).

Essa visão desencantada, encontra bastante eco entre autores contemporâneos, tais como, entre outros, Agamben (2009, p. 47), que diagnostica a catástrofe da proliferação de dispositivos que estão dessubjetivando os homens: "o que acontece agora é que processos de subjetivação e processos de dessubjetivação parecem tornar-se reciprocamente indiferentes e não dão lugar à recomposição de um novo sujeito, a não ser de forma larvar e, por assim dizer, espectral”. Para Gilles Lipovetsky (1989, p. 13), a sociedade atual “já não possui qualquer imagem gloriosa de si própria ou projeto histórico mobilizador; doravante o vazio nos governa, um vazio sem trágico nem apocalipse”. Zygmunt Bauman (2008, p. 20) também tem uma visão negativa: "A característica mais proeminente da sociedade de consumidores - ainda que cuidadosamente disfarçada e encoberta - é a transformação dos consumidores em mercadorias; ou antes, sua dissolução no mar de mercadorias”. Alain Finkielkrault (1988, p. 159) é ainda mais enfático: “A barbárie acabou por se apoderar da cultura. [...] E a vida com o pensamento cede suavemente o lugar ao face-a-face terrível e irrisório do fantástico e do zumbi.”

Há, portanto, uma profunda desconfiança em relação à experiência na contemporaneidade, não só estética, mas de toda ordem. E não é de todo inútil especularmos, como fez Nietzsche (2014, p. 17-23), se a fonte desse descontentamento com a realidade já não estaria contida no nascimento do próprio pensamento ocidental, ou mais especificamente com Sócrates e Platão. Se assim o for, o problema estaria menos na experiência estética que no pensamento lógico-racional, que busca impor as condições para que a experiência possa ser considerada experiência.

Voltando a Larrosa (2014, p. 10), quando escreve que "a experiência é algo que (nos) acontece e que às vezes treme, ou vibra, algo que nos faz pensar, algo que nos faz sofrer ou gozar, algo que luta pela expressão", não nos caberia supor que tal experiência seja acessível à grande maioria das pessoas comuns? Não passaríamos todos nós em alguns momentos justamente por essas situações? E não seria essa luta pela expressão, esse desejo de cantar, uma experiência estética, uma vontade de transcriação?

Nas palavras de Maturana, 
A experiência humana não tem conteúdo. Em nossa experiência, nós não encontramos coisas, objetos ou a natureza como entidades independentes, como nos parece na simplicidade da vida cotidiana. Nós vivemos na experiência, na práxis de viver de seres humanos no fluir de sermos sistemas vivos na linguagem, como algo que acontece em nós e a nós à medida que linguajamos (MATURANA, 2001, p. 154).

Parece-nos inegável que a vida experimentada no mundo moderno não é igual a que se experimentou ao longo da tradição e não há por que imaginar que o seja nas variações contemporâneas. Entretanto, embora a experiência não ocorra mais como supomos que ocorria, nem por isso ela deixa de ser significativa para os sujeitos da experiência, e sobretudo em sua dimensão cotidiana, agora atravessada pela estética:

\begin{abstract}
Oferecer à visão diz respeito a toda a criação no cotidiano. Esta não é uma subcultura mensurável de acordo com o referencial do bom gosto burguesista, mas possui uma qualidade intrínseca. A fotografia, como arte de massa, os clubes de pintura, as oficinas literárias, todas as formas do kitsch, do poço confeccionado com pneus aos anões de jardim, tudo isso dá testemunho de uma busca da felicidade a partir da forma (MAFFESOLI, 2007, p. 187)
\end{abstract}

Não se trata, então, de colocar a experiência ao lado do excepcional, do excêntrico ou do inenarrável, mas justamente no seio do cotidiano mais banal e repetitivo, ligada à escala humana, à celebração, à narrativa:

Em todos os setores, é a experiência a palavra-chave para explicar a relação que cada um estabelece com o grupo, a natureza, a vida em geral. Experiência que ignora escrúpulos racionais, repousando essencialmente no aspecto nebuloso do afeto, da emoção, da sintonia com o outro. É precisamente por estar a vibração na ordem do dia que convém adotar uma postura intelectual que saiba dar conta dela. [...] Perspectiva hermenêutica que está de acordo, metodologicamente, com o desenvolvimento das histórias de vida e, empiricamente, com o das homepages da Internet e outras formas romanescas de autoficção (MAFFESOLI, 2007, p. 203-204).

Como constata Favaretto (2011), a ampliação do campo da arte e da estética liquidou o princípio moderno de uma arte compromissada com o novo, com a ruptura: "A prática artística está desterritorializada, para bem e para mal; isto é, para o exercício das singularidades ou para a efetuação da razão comunicativa, quando não para o oportunismo modista" (p. 105). Este deslocamento da arte das obras para uma arte de viver manifesta-se na estetização da vida cotidiana: lugares, cenas, acontecimentos: "Assim, o alargamento da experiência artística, interessada na transformação dos processos de arte em sensações de vida, permite que se pense na possibilidade de se fundar uma estética generalizada que dê conta das maneiras de viver, da arte de viver" (p. 108).

Essa disseminação estética contemporânea requer, paradoxalmente, a desapropriação da própria estética praticada nos moldes modernos. Não mais estética como julgamento, como ciência, disputa de regras para a boa apreciação ou estudo do estado da arte pelo conjunto das obras significativas de uma época ou de seus artistas, mas abertura às proposições de toda 
ordem, às transcriações coletivas, aos embelezamentos gratuitos do mundo. Não se trata de uma hiper-estética como desejo desesperado de camuflar o vazio com a proliferação dos excessos tese de adoecimento da arte por metástase (BAUDRILLARD, 1997) -, mas de revisar as significações da estética rumo ao dinamismo das transcriações dadas ao acaso pela injeção de aparências na aparência do mundo. Estética que se afirma como intensificação da vida.

\section{Esboço para uma educação estética}

Das considerações sobre a experiência estética podemos derivar ao menos duas manifestações de reconhecimento da experiência, uma que irrompe no instante, como um choque, um trauma, uma ocorrência drástica, um evento inesperado, e outra que se consolida por meio de um movimento lento, um fluxo até certo ponto imperceptível, mas que num dado momento se faz presente, adquire forma e se revela como reflexão (autonarrativa), como conversa (conarrativa) ou como obra de arte (narrativas de toda ordem, visualidades, sonoridades). Os apreciadores das obras de arte podem, então, além da experiência estética propiciada pelo contato com a obra, também acessar outras dimensões de sua experiência de vida. Em todos os casos, o que se nota, é que a experiência quer se manifestar, quer falar, quer se expressar.

No caso das artes na contemporaneidade, dada a estetização do mundo como emergência do estético no cotidiano das massas (LIPOVETSKY; SERROY, 2015), muitas vezes a experiência estética é propiciada pela interrupção dos fluxos, pela disrupção, pela dessublimação da arte, quando então somos levados ao pasmo, à reflexão, à ressignificação de nossas próprias experiências de vida.

Poderíamos citar numerosos exemplos colhidos das obras de ficção, mas preferimos buscar nos documentários, que em princípio não se destinariam prioritariamente a uma experiência estética, essa partilha da experiência particular e cotidiana, pela qual somos expostos à intimidade dos autorretratados. É o que encontramos em E agora? Lembra-me (2013), do português Joaquim Pinto, que documenta um ano de tratamento experimental contra o vírus do HIV, com o qual o cineasta convive há duas décadas, e Irène (2009), do francês Alain Cavalier, diário em vídeo no qual rememora os anos vividos com a atriz Irène Tunc, morta em um acidente de carro na década de 70.

Em comum, guardam as mesmas características: expõem experiências particulares por meio de narrativas em primeira pessoa que se justificam menos pelo conteúdo dos enunciados que pelo modo de enunciá-los, pois partilham um conhecimento que é da ordem do sensível, 
voltado, portanto, para uma experiência estética. Não se trata tão somente de exibicionismo ou outra forma de narcisismo, embora possa conter traços, mas sobretudo da vontade de desnudamento da vida, de conferir-lhe uma dimensão estética, como modo de justificar sua existência.

A estética deixa de ser uma experiência controlada majoritariamente pelas obras de arte e passa a dominar todas as dimensões da vida mediada. É como se a vida contivesse duas esferas: a vida imediata, que se precipita sobre nós, regida pelo acaso, e a vida narrada, pela qual dispomos no tempo as experiências vividas e imaginadas. A primeira vida é insignificante, incontrolável, irremediavelmente instantânea, frágil e efêmera. A segunda está aberta às interpretações, transcriações e fruições próprias da hermenêutica, da arte e da estética.

É esta segunda esfera da vida, a mediada, que importa à educação. E com o alargamento da experiência estética, já não cabe mais à educação de sensibilidade os antigos cânones formativos, que investiam na preservação de um sujeito estável, duradouro, de identidade única. Como aponta Favaretto (2010, p. 231), em vez "de a educação significar a condução à forma de um sujeito constituído, trata-se agora da destituição, da deposição desse sujeito, garantia da unidade da experiência. Justamente neste deslocamento estaria a contribuição efetiva da arte":

$\mathrm{O}$ agora exposto significa que

\begin{abstract}
as obras, os experimentos, as proposições de toda sorte, funcionam como interruptores da percepção, da sensibilidade, do entendimento; funcionam como um descaminho daquilo que é conhecido. Uma espécie de jogo com os acontecimentos, de táticas que exploram ocasiões em que o sentido emerge através de diç̧ões e timbres, nas formas não nos conteúdos; uma viagem pelo conhecimento e pela imaginação: são imagens que procuram captar o tipo de deslocamento da subjetividade promovido pelas obras da arte (FAVARETTO, 2010, p. 232).
\end{abstract}

A estética deixa de se definir, neste cenário, como ciência do belo e passa a incorporar a noção nietzschiana de fisiologia aplicada, que pode ser compreendida em associação

\footnotetext{
aos processos de assimilação e regulação do organismo como um todo e aos instintos e atividades que potencializam ou diminuem a sua vitalidade, incluindo assim tanto o âmbito 'físico' (digestão, circulação sanguínea, ruminação, etc.), quanto o âmbito 'psíquico' (os afetos, os instintos, os estímulos nervosos, etc.) (BITTENCOURT, 2010, p. 3).
}

As experiências estéticas, incluindo aqui as proporcionadas pela apreciação das obras de arte, operam na intensificação da vida, compreendida em sua dimensão fisiológica, corpórea, tanto física quanto psiquicamente. Como afirma Benítez (2012, p. 27), a arte em Nietzsche afeta tanto o que é da ordem biológica (o corpo) quanto fisiológica (as pulsões inconscientes), portanto, é menos um "estado espiritual" que uma "motivação orgânica", uma sugestão aos músculos e aos sentidos. 
A experiência estética é, pois, uma experiência de excitação, opera como "meio de proporcionar experiência imediata", como "o órgão sensorial da cultura, por intermédio do qual ela sorve o concreto imediato" (FLUSSER, 2013, p. 381). É uma retomada da aisthesis em seu sentido grego, que indica a "capacidade sensível do ser humano para perceber e organizar os estímulos que lhe alcançam o corpo" (DUARTE JUNIOR, 2004, p. 136).

Essa dimensão estética da experiência requer, portanto, uma educação de sensibilidade que se dirija "para aquele saber primeiro que veio sendo sistematicamente preterido em favor do conhecimento intelectivo, não apenas no interior das escolas, mas ainda e principalmente no âmbito familiar de nossa vida cotidiana" (DUARTE JUNIOR, 2004, p. 14). É o que também aponta Silvia Pillotto (2007, p. 114) ao defender a educação do e pelo sensível por meio da “intuição, criação, percepção, sensibilidade, sobretudo".

Nessa perspectiva, ao lado do conhecimento cognitivo, buscam-se itinerários de (auto)formação que reconheçam a importância educacional das experiências estéticas. A finalidade dessa educação de sensibilidade é "chegar a ser o que se é", divisa que Nietzsche (1995) tomou de Píndaro ("torna-te o que tu és") para apontar o difícil caminho da individuação, o qual não pode ser atingido pela via direta, pelo cognitivo, mas pela mediação da experiência estética:

O eu que importa é aquele que há sempre além daquele que se toma habitualmente por sujeito: não está por descobrir, mas por inventar; não por realizar, mas por conquistar; não por explorar, mas por criar da mesma maneira que um artista cria uma obra. Para chegar a ser o que se é, tem que ser artista de si mesmo (LARROSA, 2009, p. 65).

Isso não significa que temos de seguir os passos de Nietzsche ou de qualquer outro, mas assim como Nietzsche tornou-se Nietzsche, temos de nos tornarmos nós mesmos, isto é, engendrarmos nossa singularidade, "criar um personagem que incorpora e faz uso de tudo o que lhe é genuinamente próprio, e que seria inteiramente ele mesmo - o que exclui qualquer imitação” (GIACOIA JUNIOR, 2014, p. 260). Isso só é possível pela adesão à vida, que passa a ser vivida com arte e como arte: "governar a própria vida para lhe dar a forma mais bela possível" (FOUCAULT, 2006, p. 244), ou ainda: “nós, porém, queremos ser os poetas da nossa vida e, em primeiro lugar, das coisas mais pequenas e comuns" (NIETZSCHE, 2001, §299).

Eis, ao fim e ao cabo, a finalidade da experiência estética e da educação de sensibilidade: tornarmo-nos artistas de nós mesmos, compreender que a vida, em sua justificativa estética, pode ser vivida como obra de arte. 


\section{Referências}

AGAMBEN, Giorgio. O que é o contemporâneo? e outros ensaios. Trad. de Vinícius Nicastro Honesko. Chapecó, SC: Argos, 2009.

ALMEIDA, Rogério de. O Criador de Mitos: imaginário e educação em Fernando Pessoa. São Paulo: Educ, 2011.

BACHELARD, Gaston. L'Air et les Songes. Essai sur l'imagination du mouvement. Paris: Le Libre de Poche/Librairie José Corti, 2004.

BAUDRILLARD, Jean. A arte da desaparição. Trad. de Anamaria Skinner. Rio de Janeiro: Editora UFRJ/N-Imagem, 1997.

BAUMAN, Zygmunt. Vida para consumo: a transformação das pessoas em mercadoria. Trad. de Carlos Alberto Medeiros. Rio de Janeiro: Zahar, 2008.

BENÍTEZ, Roberto Sánchez. La recuperación de lo trágico: música y humanismo. Monterrey, México: Cecyte, N. L.-CAEIP, 2012.

BITTENCOURT, Renato N. Estética como fisiologia aplicada em Nietzsche. VisoCadernos de estética aplicada. n. 8, jan-jun., 2010.

CAMPOS, Haroldo de. A arte no horizonte do provável e outros ensaios. São Paulo: Perspectiva, 1969.

CASSIRER, Ernst. Ensaio sobre o Homem: introdução a uma filosofia da cultura humana. Trad. Tomás R. Bueno. São Paulo: Martins Fontes, 1994.

DELEUZE, Gilles \& GUATTARI, Félix. O que é a filosofia? Trad. de Bento Prado Jr. e Alberto Alonso Muñoz. São Paulo: Editora 34, 1992.

DUARTE JUNIOR, João. F. O sentido dos sentidos: a educação (do) sensível. Curitiba: Criar edições, 2004.

DURAND, Gilbert. A imaginação simbólica. Trad. de Eliane Fittipaldi Pereira. São Paulo: Cultrix/EDUSP, 1988.

DURAND, Gilbert. As Estruturas Antropológicas do Imaginário. Trad. de Hélder Godinho. São Paulo: Martins Fontes, 1997.

DURAND, Gilbert. Campos do Imaginário. Lisboa: Instituto Piaget, 1998.

FAVARETTO, Celso F. Arte Contemporânea e Educação. Revista Iberoamericana de Educación, n ${ }^{\circ}$ 53, p. 225-235, 2010.

FAVARETTO, Celso. F. Deslocamentos: entre a arte e a vida. ARS (São Paulo), v. 9, p. 94$109,2011$.

FERREIRA-SANTOS, Marcos; ALMEIDA, Rogério de. Aproximações ao Imaginário: 
bússola de investigação poética. São Paulo: Képos, 2012.

FINKIELKRAUlT, A. A Derrota do Pensamento. Trad. de Mônica Campos de Almeida. Rio de Janeiro: Paz e Terra, 1988.

FLUSSER, Vilém. "Nossa embriaguez". In: DUARTE, Rodrigo (org.). O belo autônomo: textos clássicos de estética. $3^{\mathrm{a}}$ ed. Belo Horizonte: Autêntica/Crisálida, 2013.

FOUCAUlT, Michel (2006). Ditos e Escritos - Vol. V: Ética, Sexualidade, Política. Rio de Janeiro: Forense Universitária.

GIACOIA JUNIOR., Oswaldo. Nietzsche: o humano como memória e como promessa. Petrópolis, RJ: Vozes, 2014.

KOSLOWSKI, Adilson. Acerca do problema da definição de arte. Revista Húmus, $\mathrm{n}^{\circ} 8$, Mai/Jun/Jul/Ago, 2013.

LARROSA, Jorge. Nietzsche \& a Educação. Trad. de Semíramis Gorini da Veiga. $3^{\mathrm{a}}$. ed. Belo Horizonte: Autêntica, 2009.

LARROSA, Jorge. Tremores: escritos sobre experiência. Trad. de Cristina Antunes e João Wanderley Geraldi. Belo Horizonte: Autêntica, 2014.

LIPOVETSKY, Gilles. A Era do Vazio. Lisboa: Relógio D’Água, 1989.

LIPOVETSKY, Gilles; SERROY, Jean. A estetização do mundo: viver na era do capitalismo artista. São Paulo: Companhia das Letras, 2015.

MAFFESOLI, Michel. O ritmo da vida: variações sobre o imaginário pós-moderno. Trad. de Clóvis Marques. Rio de Janeiro: Record, 2007.

MATURANA, Humberto. Cognição, ciência e vida cotidiana. Belo Horizonte: UFMG, 2001.

NIETZSCHE, Friedrich. A Gaia Ciência. São Paulo, Companhia das Letras, 2001.

NIETZSCHE, Friedrich. Crepúsculo dos ídolos ou como se filosofa com o martelo. Trad. de Jorge Luiz Viesenteiner. Rio de Janeiro: Vozes, 2014.

NIETZSCHE, Friedrich. Ecce homo. Como alguém se torna o que é. Trad. de Paulo César de Souza. São Paulo: Companhia das Letras, 1995.

NIETZSCHE, Friedrich. Genealogia da moral. São Paulo: Companhia das Letras 1998.

NIETZSCHE, Friedrich. O Nascimento da tragédia. Ou Helenismo e Pessimismo. São Paulo: Companhia das Letras, 1999.

PESSOA, Fernando. O Eu profundo e os outros Eus. Rio de Janeiro: Nova Fronteira, 1980.

PILLOTTO, Silvia S. D. Educação pelo sensível. Linguagens - Revista de Letras, Artes e Comunicação. Blumenau, v. 1, n. 2, p. 113-127, mai/ago, 2007. 
RANCIÈRE, Jacques. O Inconsciente Estético. Trad. de Mônica Costa Netto. São Paulo: Ed. 34, 2009.

RICOEUR, Paul. O conflito das interpretações: ensaios de hermenêutica. Porto/Portugal: Rés, 1969.

RICOEUR, Paul. Hermenêutica e Ideologias. Petrópolis, RJ, Vozes, 2008.

ROSSET, Clément. A lógica do Pior: elementos para uma filosofia trágica. Trad. de Fernando J. F. Ribeiro e Ivana Bentes. Rio de Janeiro: Espaço e Tempo, 1989.

STEINER, George. Depois de Babel: questões de linguagem e tradução. Trad. de Carlos Alberto Faraco. Curitiba: Editora da UFPR, 2005. 